\title{
||||||||||||||||||||||||||||||||||||||||||||||||||||||||||||||||||.
}

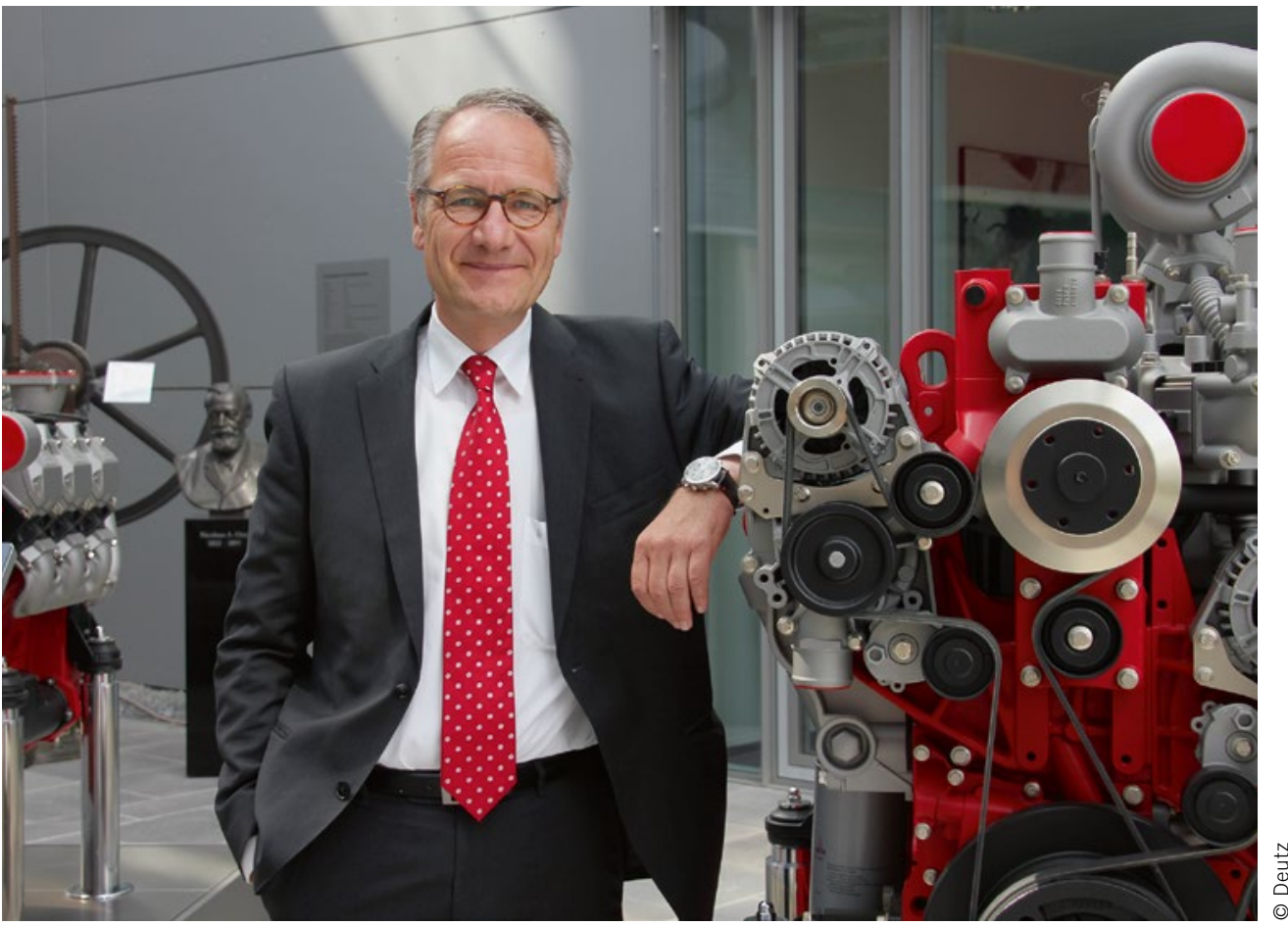

Dr. Markus Schwaderlapp Head of Research and Development at Deutz AG

\section{Decarbonisation in the Agricultural Sector}

Powerful engines and high energy storage capacity are essential requirements in the agricultural sector. This is why diesel always has been and still is the drive system of choice. A 590-1 tank of diesel can, for example, keep a heavy tractor ploughing at high load for around $10 \mathrm{~h}$. By comparison, in order to achieve the same amount of work using the standard battery technology available today, a purely electric drive system would need to be equipped with a battery pack with a volume of some $4500 \mathrm{l}$ and weighing $12 \mathrm{t}$.

Nonetheless, it is possible for the agricultural sector to reduce its $\mathrm{CO}_{2}$ emissions (decarbonisation). Using alternative fuels and electrifying power take-offs can significantly increase the efficiency of combustion engines still further; there is even a possibility that engines could be run $\mathrm{CO}_{2}$ neutral. The choice of fuels available extends from gas and biofuels, hydrotreated vegetable oils (HVOs) produced from recycled vegetable oils or waste fats to e-fuels, identical to diesel, based on electricity produced using regenerative methods.

As part of a research project, $\mathrm{CO}_{2}$ reductions of up to $24 \%$ with a natural gas powered 3.6 l engine installed in a Same Deutz-Fahr tractor are achieved. By using biogas, the operation would even be $\mathrm{CO}_{2}$ neutral. Biofuels or HVOs are made of renewable, sustainably produced bio-raw materials and run $\mathrm{CO}_{2}$ neutral because the plants absorb $\mathrm{CO}_{2}$ from the atmosphere as they grow. The same principle applies in the case of e-fuels: in their production, the same volume of $\mathrm{CO}_{2}$ is absorbed from the atmosphere as is emitted during the combustion process. Running an engine with synthetic diesel fuel such as this is particularly convenient because it can be used with fossil-based diesel in any ratio. The relevant approvals for using these fuels in series production engines have already been issued.

A further approach is to use hydrogen directly in combustion engines. To prove this, Keyou, a Munich-based business start-up is already running a 7.8-1 six-cylinder engine in a highly-promising prototype. We will thus see further diversification in terms of fuel types in future. It is important that manufacturers offer the right solutions early on - it is the market that will ultimately decide which concepts become established.

At the same time, further evolution of the combustion engine will be helped by electrifying the entire drive system. The first step is the mild hybridisation of the engine by installing a $48-\mathrm{V}$ system. This will offer the agricultural sector in particular a wide range of options for running power take-offs using electrical power. The load on the combustion engine will be reduced, thus improving the efficiency of the overall system and lowering operating costs. Alternative fuels and electrification, particularly when combined, represent real progress towards effective decarbonisation. 